\title{
Cytotaxonomic studies of three ornamental aroids
}

\author{
Emmanuel Jonah Kalu, Anulika Mercy Kanu
}

Abia State Polytechnic, Aba, Nigeria

\begin{abstract}
Cytotaxanomical analysis carried out on three ornamental aroids (Anchomanes difformis, Anchomanes hookeri and Arum maculatum) proved that cytological studies is none negligible tool in phylogeny and scientific classificationns of plants. Aceto-orcein stain squash technique was used in this study. Anchomanes difformis and Anchomanes. hookeri showed more relatedness in chromosome number and chromosome morphology, sharing the same chromosome number $2 \mathrm{n}=13$, while Arum maculatum has $2 n=8$. The following karyotypes formular were revealed: $2 n=8=3 M+3 S M+2 S T$ in Arum maculatum; $2 \mathrm{n}=13=5 \mathrm{M}+1 \mathrm{SM}+7 \mathrm{ST}$ in A. difformis; and $2 \mathrm{n}=13=3 \mathrm{M}+6 \mathrm{SM}+4$ A. hookeri. Other karyotype parameters investigated like CI\%, AsI and degree of asymmetry of the genomes supported current taxonomic ranking.
\end{abstract}

Keywords: aceto-orcein; Arum maculatum; Anchomanes hookeri; Anchomanes difformis; Karyotype; asymmetry

\section{INTRODUCTION}

Araceae is a group of monocotyledon flowering plants that bear a type of inflorescence called spadix. The spadix is usually enclosed in spathe or leaf-like bracts. The group belongs to the order Alismatales. Members are colloquially called aroid. They are herbaceous and often rhizomatous or tuberous.

Arum maculatum is a common woodland plant species, commonly known as arum, Jack in the pulpit, lords and ladies etc. it bears spadix enclosed by pale green spathe. They are monoecious and the female flowers form rings at the base while rings of male flower are at the top of the spadix. They bear poisonous red berries that remains long after the leaves and the flower have withered away. They bear starch storing roots. Bromfield (1856) identified two types based on the leave spot. The spotted and unspotted.

Anchomanes difformis (Engl) is a species of flowering plants in the family Araceae. It is herbaceous plant with pricky petiole, having huge divided leaf and spathe and the solitary leaf arise from a horizontal tuber. They normally grow as wild but sometimes are cultivated as ornamentals. They are native to West Africa (Eneojo et al, 2011). Afolayan, et al (2012) reported high potential for industrial applications especially in the food, textile and pharmaceutical industries (Eneojo et al, 2011). It is locally called "Oje" by the Igbos in East of Nigeria. 
Anchomanes hookeri (Schott) is a large herbaceous plant with stout pricky stem, which grow to $3 \mathrm{ft}$. or more in height with obovota leaves and palmate veination (Brown, 1902). The stem and the adaxial surface of the leaves have spines, the roots barely grow deep into the ground but can grow horizontally up to $13 \mathrm{~cm}$. It takes a long time to completely unfold its leaves after breaking the soil. Its tubers are flattened, roughly spherical and weighing as much as $5-15 \mathrm{~kg}$.

Karyotype and related studies have proved to be relevant tool in determining karyoevolutionary trends within taxa (Srivastava and Srivastava, 2000; Hamidah et al, 2009). Recently, karyotype studies have contributed enormously to the systematic along with biochemistry, molecular, morphological and anatomical studies.

\section{MATERIALS AND METHODS}

\section{1. Supply of Root Tips}

For karyotype studies and for the study of chromosome numbers, the plants of the three species were grown in saw-dust culture because the root tips needed for the studies are very delicate and if sown in soil can break in the process of uprooting and the particles do not adhere tightly and so can allow for the easy uprooting of the plants without breaking the delicate root tips

\section{2. Chromosome Investigation}

Chromosome studies involve a number of steps such as determining the best harvest time for root tips, pretreatment, fixation, hydrolysis, squashing, staining and chromosome analysis. These steps are necessary so that on squashing and staining, chromosome would appear as distinct shortened, single bodies scattered within a given cell thus permitting easy counting and measurements. Thus metaphase plate is always preferred and was used.

\section{3. Harvest Time for Root Tips}

The time of collection of root tips is of prime importance because it is desirable to arrest enough metaphase plates. This involved collection of root tips at half hourly interval from 9 a.m. to 3 p.m.

\section{4. Pretreatment and Fixation}

Pretreatment is aimed at clearing the viscosity of the cytoplasm in the root tips and also a means of shortening the chromosome and inhibiting the formation of spindles, resulting in 'thick', distinct and disorganized bodies of chromosome. Two chemicals normally used are $0.003 \mathrm{M} 8$-hydrooxyquinoline and $0.1 \%$ colchicines. The procedure applied involved cutting root tips about $4 \mathrm{~cm}$ long and a slit made at the cut end so as to enhance the absorption of the chemical by the root tips.

The plant materials were immediately immersed in the pretreatment solution and kept at room temperature of about $20{ }^{\circ} \mathrm{C}$ for two hours before storing in the refrigerator at a temperature of $4{ }^{\circ} \mathrm{C}$ for 2-3 hours. This low temperature treatment aided the shortening of the chromosome. The result presented here were obtained with 8-hydrooxyquinoline. Carnoy's solution I, a mixture of absolute alcohol and glacial acetic acid in the ratio 3: 1 was the fixative used. For fixation, the pretreated roots were put in specimen bottles containing the solution and left in the refrigerator at $4{ }^{\circ} \mathrm{C}$ for at least 24 hours. 
Fixation kills and stabilizes the root tips rapidly thus preserving them in a near natural condition for a long time.

\section{5. Hydrolysis}

After fixation, the roots were hydrolyzed with $0.1 \mathrm{~N} \mathrm{HCL}$ at $60{ }^{\circ} \mathrm{C}$ in a water bath. This helped to soften the root tissues and enhanced the absorption of stain. To obtain a good result, series of time were tried ranging from three to fifteen minutes.

The optimal results were obtained using $0.1 \mathrm{~N} \mathrm{HCl}$ for 12 minutes for all the three species and 7 minutes, using $1 \mathrm{~N} \mathrm{HCl}$ also for all the species. The reason for long period of hydrolysis was that roots were big and often with tough 'skin' covering.

\section{6. Squashing and Staining}

Squashing is aimed at separating the cells from one another to enhance the study of chromosome. The aim of staining is to bring about contrast between the chromosomes which remained stained.

After hydrolysis, the root tips appeared milky in color and were washed four times with distilled water. A root tip was then placed on a clean slide on top of a filter paper. The milky tip was next cut with scapel and sliced into fine bits in two drops of stain-aceto orcein. Thick particles were removed.

After staining, the cover slip was placed in position and filter paper was folded over the slide just to remove excess stain. A gentle tapping with a match stick was given so as to further scatter the chromosomes two ends of the filter paper were again folded over the slide and then pressed with the right thumb. This helped to further spread the chromosomes, expel any trapped air as well as blot out the excess stain.

\section{7. Slide Preservation}

For temporary preservations, the sides of the cover slip were sealed with a nail varnish which preserved the cell for up to one week. For permanent preparations, the slides were first smeared with egg albumen and allowed to dry. This served as an adhesive. Squashes were made on the slide and a cover slip put in place and pressed down as normal.

Inspection was then made at a lower power to ensure that the slide had a reasonable number of diving cells. A razor blade was used to sharply lift the cover slip from the slide. Both cover slip and slide were passed through grades of alcohol for 30 seconds beginning with 50-75-90\% - Absolute - Absolute alcohol / xylene [50\%: $50 \%$ ] and then finally xylene for 1 minute. After xylene a drop of Canada balsam was added to the squashing position on the slide and fresh cover slip was carefully lowered. On another slide, another drop of Canada balsam was added and the original cover slip was placed making sure that no air bubbles were entrapped. Inspections were then made and a good slide was allowed to dry for 24 hours.

\section{8. Karyotype Analysis}

Chromosomes at metaphase were measured according to previous studies (Kalvande et al, 2012; Hamidah et al,2009; Hejazi, 2011; Gonzalez et al, 2013; Truta et al, 2013; Lavania and Srivastava , 1992; and Gunjan and Roy, 2010). Chromosome designation followed Levan et al. (1964), and the homology was assigned according to similarities in length, morphology, and centromere position, respectively, on the basis of CI (Centromeric Index) and $\mathrm{r}$ (arm ratio) values. Thus, the chromosomes are metacentric when they have a mean arm ratio $\mathrm{r}(\mathrm{r}$ 
$\leq 1.7$ and $\mathrm{CI}=37.5-50.0)$ submetacentric $(\mathrm{r}=1.70-2.99, \mathrm{CI}=25.0-37.5)$, subtelocentric $(\mathrm{r}=3.00-6.99$ and $\mathrm{CI}=12.5-25.0)$, or telocentric $(\mathrm{r} \geq 7.00$ and $\mathrm{CI} \leq 12.5)$ (Truta et al, 2013). In karyotype, the chromosome pairs were grouped in descending order of their length. The karyotypes were characterized numerically estimating the followings: long arm (LA), short arm (SA), absolute length of each chromosome CL [LA+SA], arm ratio R[LA/SA], centromeric index (CI) [SA/CL]. To evaluate the karyotype asymmetry /symmetry, the following estimates were used:

The total form percent (TF \%).

$$
T F \%=\left(\frac{\sum S A}{\sum C L}\right)
$$

Asymmetry Index (AsI\%) (synonymous with Ask\%)

$$
A s I \%=\left(\frac{\sum L A}{\sum C L}\right) \times 100
$$

The intrachromosomal asymmetry idex $\left(\mathrm{A}_{1}\right)$ and the interchromosomal asymmetry index $\left(A_{2}\right)$ were calculated according to (Srivastava and Srivastava, 2000; Truta et al, 2013)

$$
\mathrm{A} 1=\left\lfloor 1-\left(\sum \frac{S A}{S A}\right) / n\right\rfloor
$$

where SA stand for the mean of short arm, LA is the mean of the long arm, (n) is the number of homologues chromosomes. It measures the average position of the centromere in karyotype and ranges from 0 (completely symmetrical) to 1 (completely asymmetrical).

$$
A 2=\left(\frac{S C L}{X C L}\right)
$$

where $\mathrm{S}_{\mathrm{CL}}=$ standard deviation of chromosome length, $\mathrm{X}_{\mathrm{CL}}=$ mean chromosome length for each genotype. It is defined as a coefficient to evaluate heterogeneity of chromosome length.

Karyotypic characteristics were determined using the symmetry classes of Stebbins (SC) (Stebbins, 1971).

\section{RESULTS}

Table 1. The classification of karyotypes in relation to their degree of asymmetry according to stebbins (1971).

\begin{tabular}{|c|c|c|c|c|}
\hline & \multicolumn{4}{|c|}{ Proportion of chromosomes with arm ratio $>2$} \\
\hline Ratio (Largest/smallest) & 1.00 & $0.99-0.51$ & $0.50-0.01$ & 0.00 \\
\hline$<2(\mathrm{~A})$ & $1 \mathrm{~A}$ & $2 \mathrm{~A}$ & $3 \mathrm{~A}$ & $4 \mathrm{~A}$ \\
\hline $2-4(\mathrm{~B})$ & $1 \mathrm{~B}$ & $2 \mathrm{~B}$ & $3 \mathrm{~B}$ & $4 \mathrm{~B}$ \\
\hline$>4(\mathrm{C})$ & $1 \mathrm{C}$ & $2 \mathrm{C}$ & $3 \mathrm{C}$ & $4 \mathrm{C}$ \\
\hline
\end{tabular}


Table 2. Average of cytogenetic parameters of Arum maculalum utilized for idiogram construction $(\mathrm{CL}=$ chromosome lenght, $\mathrm{LA}=$ long arm lenght, $\mathrm{SA}=$ short arm lenght, $\mathrm{AR}=$ arm ratio $(\mathrm{LA} / \mathrm{SA})$, $\mathrm{CI}=$ Centromeric index, $\mathrm{RL}=$ relative length .

\begin{tabular}{|c|c|c|c|c|c|c|c|}
\hline & TYPE & CL & LA & SA & AR & CI & RL \\
\hline 1 & SM & 2.10 & 1.40 & 0.70 & 2.00 & 33.33 & 4.69 \\
\hline 2 & SM & 4.20 & 2.80 & 1.40 & 2.00 & 33.33 & 9.39 \\
\hline 3 & SM & 4.55 & 3.15 & 1.40 & 2.25 & 30.77 & 10.17 \\
\hline 4 & $\mathrm{M}$ & 5.60 & 2.80 & 2.80 & 1.00 & 50.00 & 12.51 \\
\hline 5 & $\mathrm{M}$ & 5.60 & 2.80 & 2.80 & 1.00 & 50.00 & 12.51 \\
\hline 6 & $\mathrm{ST}$ & 5.60 & 4.20 & 1.40 & 3.00 & 25.00 & 12.51 \\
\hline 7 & $\mathrm{ST}$ & 7.35 & 5.60 & 1.75 & 3.20 & 23.81 & 16.42 \\
\hline 8 & $\mathrm{M}$ & 9.45 & 5.60 & 3.85 & 1.45 & 40.74 & 21.11 \\
\hline $\mathrm{T}$ & & 44.45 & 28.35 & 16.10 & & 286.98 & 99.99 \\
\hline $\mathrm{M}$ & & & & & & & \\
\hline
\end{tabular}

Table 3. Average values of cytogenetic parameter of Anchomanes difformis utilized for idiogram construction $(\mathrm{CL}=$ chromosome lenght, $\mathrm{LA}=$ long arm lenght, $\mathrm{SA}=$ short arm lenght, $\mathrm{AR}=$ arm ratio $(\mathrm{LA} / \mathrm{SA}), \mathrm{CI}=$ Centromeric index, $\mathrm{RL}=$ relative lenght).

\begin{tabular}{|c|c|c|c|c|c|c|c|}
\hline & TYPE & CL & LA & SA & AR & CI & RL \\
\hline 1 & ST & 5.90 & 4.50 & 1.40 & 3.21 & 23.73 & 4.02 \\
\hline 2 & ST & 9.10 & 7.70 & 1.40 & 5.50 & 15.39 & 6.20 \\
\hline 3 & ST & 9.10 & 7.70 & 1.40 & 5.50 & 15.39 & 6.20 \\
\hline 4 & ST & 9.80 & 8.40 & 1.40 & 6.00 & 14.29 & 6.68 \\
\hline 5 & SM & 9.90 & 7.10 & 2.80 & 2.54 & 28.28 & 6.74 \\
\hline 6 & M & 10.50 & 5.25 & 5.25 & 1.00 & 50.00 & 7.16 \\
\hline 7 & M & 10.85 & 6.65 & 4.20 & 1.58 & 38.71 & 7.40 \\
\hline 8 & ST & 12.60 & 9.80 & 2.80 & 3.50 & 22.22 & 8.59 \\
\hline
\end{tabular}




\begin{tabular}{|c|c|c|c|c|c|c|c|}
\hline 9 & $\mathrm{M}$ & 12.60 & 7.00 & 5.60 & 1.25 & 44.44 & 8.59 \\
\hline 10 & ST & 13.30 & 10.50 & 2.80 & 3.75 & 21.05 & 9.07 \\
\hline 11 & ST & 14.00 & 11.20 & 2.80 & 4.00 & 20.00 & 9.54 \\
\hline 12 & $\mathrm{M}$ & 14.35 & 8.40 & 5.95 & 1.41 & 41.46 & 9.78 \\
\hline 13 & $\mathrm{M}$ & 14.70 & 7.35 & 7.35 & 1.00 & 50.00 & 10.02 \\
\hline $\mathrm{T}$ & & 146.70 & 101.55 & 45.15 & & 384.96 & 99.99 \\
\hline
\end{tabular}

Table 4. Average values of cytogenetic parameter of Anchomanes hookeri utilized for idiogram construction $(\mathrm{CL}=$ chromosome lenght, $\mathrm{LA}=$ long arm lenght, $\mathrm{SA}=$ short arm lenght, $\mathrm{AR}=$ arm ratio $(\mathrm{LA} / \mathrm{SA}), \mathrm{CI}=$ Centromeric index, $\mathrm{RL}=$ relative lenght $)$.

\begin{tabular}{|c|c|c|c|c|c|c|c|}
\hline & TYPE & CL & LA & SA & AR & CI & RL \\
\hline 1 & ST & 8.40 & 7.00 & 1.40 & 5.00 & 16.67 & 5.09 \\
\hline 2 & ST & 8.40 & 6.30 & 2.10 & 3.00 & 25.00 & 5.09 \\
\hline 3 & ST & 9.10 & 7.00 & 2.10 & 3.33 & 23.08 & 5.51 \\
\hline 4 & SM & 11.55 & 8.05 & 3.50 & 2.30 & 30.30 & 6.99 \\
\hline 5 & M & 11.90 & 7.05 & 4.90 & 1.44 & 41.18 & 7.20 \\
\hline 6 & M & 11.90 & 5.95 & 5.95 & 1.00 & 50.00 & 7.20 \\
\hline 7 & SM & 12.60 & 8.40 & 4.20 & 2.00 & 33.33 & 7.63 \\
\hline 8 & ST & 12.60 & 9.80 & 2.80 & 3.50 & 22.22 & 7.63 \\
\hline 9 & SM & 13.30 & 8.75 & 4.55 & 1.92 & 34.21 & 8.05 \\
\hline 10 & M & 13.65 & 8.40 & 5.25 & 1.60 & 38.46 & 8.26 \\
\hline 11 & SM & 15.40 & 10.50 & 4.90 & 2.14 & 31.82 & 9.32 \\
\hline 12 & SM & 16.10 & 11.90 & 4.20 & 2.83 & 26.09 & 9.75 \\
\hline 13 & SM & 20.30 & 14.70 & 5.60 & 2.63 & 27.59 & 12.29 \\
\hline T & & 165.20 & 113.20 & 51.40 & 32.7 & 399.95 & 100.01 \\
\hline & & & & & & & \\
\hline & & & & & & & \\
\hline
\end{tabular}


Table 5. Karyotype characteristics of the three aroids.

\begin{tabular}{|c|c|c|c|c|c|c|c|c|}
\hline SPECIES & KARYOTYPE & CI $\%$ & $\mathrm{R}$ & AsI & TF & A1 & A2 & CLASSES \\
\hline A. maculatom & $2 \mathrm{n}=8=3 \mathrm{M}+3 \mathrm{SM}+2 \mathrm{ST}$ & 35.87 & 4.50 & 63.35 & 35.98 & 0.923 & 0.367 & $3 \mathrm{C}$ \\
\hline A. difformis & $2 \mathrm{n}=13=5 \mathrm{M}+1 \mathrm{SM}+7 \mathrm{ST}$ & 29.61 & 2.49 & 69.22 & 30.78 & 0.966 & 0.219 & $3 \mathrm{~B}$ \\
\hline A. hookeri & $2 \mathrm{n}=13=3 \mathrm{M}+6 \mathrm{SM}+4 \mathrm{ST}$ & 30.77 & 2.42 & 68.52 & 31.11 & 0.965 & 0.249 & $3 \mathrm{~B}$ \\
\hline
\end{tabular}
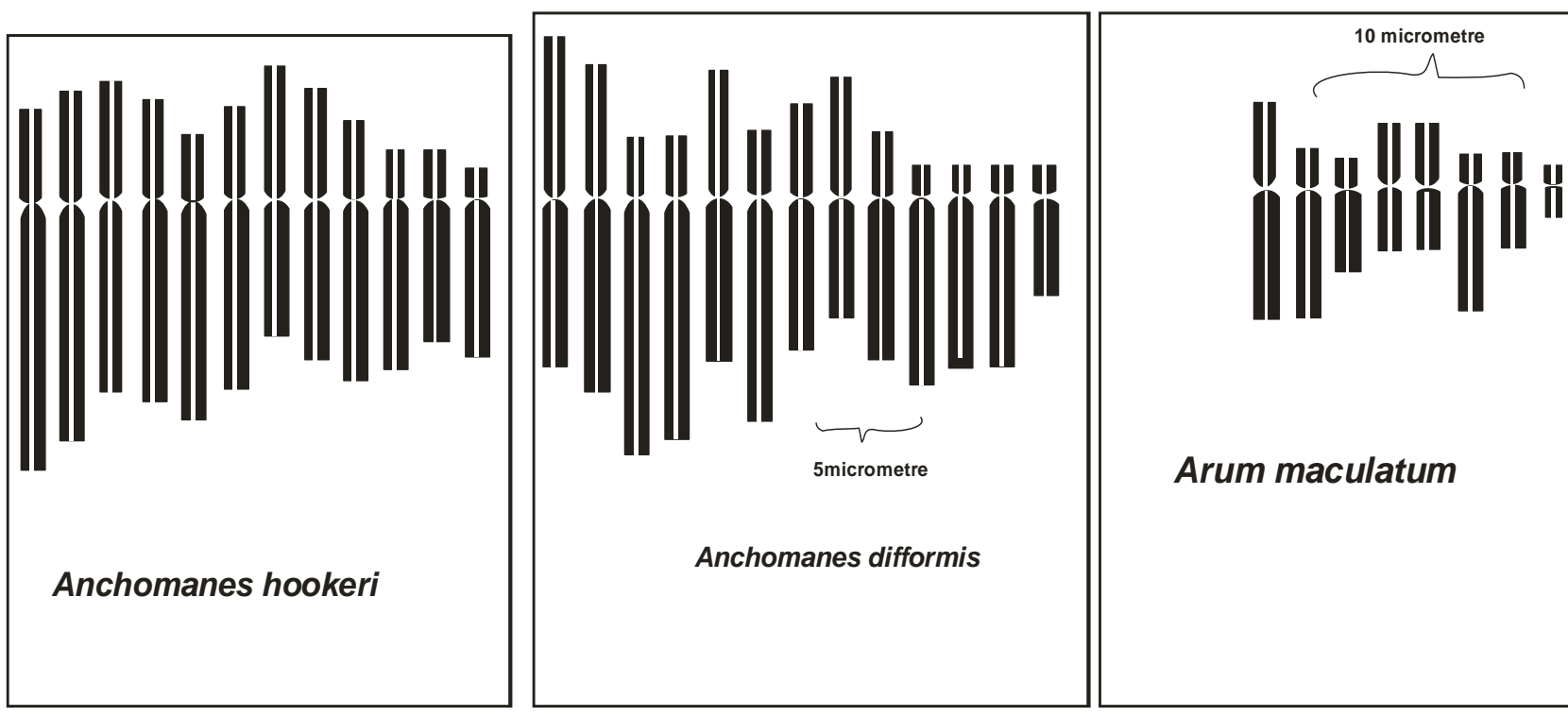

Fig. 1. Ideogram.

\section{DISCUSSIONS AND CONCLUSIONS}

Arum maculatum is morphologically distinct from the other two Anchomanes in this study. The true reason of investigating the Arum along the Anchomanes is to prove a concomitant distinction in their karyograms. The first indicator is the chromosomal numbers. In Arum maculatum $2 n=8$ while in both Anchomanes, $2 n=13$. The TF, total form percent that is used to show what percentage of the total chromosome constitutes the short arm indicated $35.98 \%$ for Arum maculatum, $30.78 \%$ for A. difformis and $31.11 \%$ for A. hookeri. A lucid picture is made to manifest in these data. The dissociation between the Arum and the Anchomanes; and then the relatedness of $A$. difformis to $A$. hookeri is put in the picture. The slight difference shown between the Anchomanes also qualifies them to be proclaimed different species.

The AsI, the asymmetric index, a measure of the genomes long arm indicated a visible line of demarcation that is associated with the taxonomic ranking. The following AsI $\% 63.35$ $\%, 69.22 \%$ and $68.52 \%$ for Arum maculatum, A. difformis and A. hookeri respectively. The difference between Arum and Anchomanes are significant. 
The karyotype (see Table 5) indicated metacentric, submetacentric and subtelocentric chromosomes in the three plants. A. difformis has more than half of its diploid chromosome to be subtelocentric (7ST) and $A$. hookeri has 4ST chromosomes while Arum maculatum has only $2 \mathrm{ST}$ chromosomes.

Truta et al (2013) A1 measures the length of short and long arms of each pair of homologues and the average position of the centromere in the karyotype and ranges from 0 (completely symmetrical) to 1 (completely asymmetrical) (Paknia and Karimzadeh, 2010). A1 analyses in this study showed 0.923 for Arum maculatum, 0.966 for A. difformis and 0.965 for $A$. hookeri (Peruzzi et al, 2009).

The idiogram (see Fig. 1) tries to picture the karyomorph. It shows the chromosome number; the relationship between each short arm to the long arm of genomes and the degree of specialization, which is also the degree of asymmetry. According to Stebbins (1950), more primitive plants show high symmetrical chromosome structures. It then means that Arum maculatum is primitive to the Anchomanes and that $A$. difformis is specialized than $A$. hooker $i$ as indicated by their chromosomal symmetry.

The karyomorph differences indicates structural changes in their chromosomes that may results from inversions, deletions, translocations etc.

\section{References}

[1] Afolayan M. O., M. O. Omojola, A. P. Onwualu, S. A. Thomas (2012). Furhter physicochemical characterization of Anchomanes difformis starch Agri. Biol. J. North Ameri., 3(1); 31-38.

[2] Brown E. N. (1902). Flora of Tropical Africa. 8: 137. www.plants.jstor.org/flora/flota014481

[3] Eneojo A. S., L. O. Egwari, T. O. Mosaku (2011). In vitro antimicrobial screening on Anchomanes difformis (Blume) Engl. Leaves and rhizomes against selected pathogens of public health importance. Advan. Biol. Res., 5(4): 221-225.

[4] Gonzalez G. E., M. F. Fourasti, J. Camara-Hernandez, L. Poggio. (2013). Comparative study of Zea karyotype. Maize Genetics cooperation newsletter, 87; 50.

[5] Gunjan K., B. K. Roy (2010). Karyotype studies in dominant species of Aloe from Eastern India. Caryologia, 63(1); 41-49.

[6] Hamideh J., S. M. H. Hejazi, M. S. Bayer (2009). Karyotypic studies of three Thymus (Lamiaceae) species and population in Iran. Caryologia, 62(4); 316-325.

[7] Hejazi S. M. H. (2011). Karyological study on three Cicer L. species (Fabaceae) in Iran. Asia J. of cell Biol., 6: 97-104.

[8] Kalvadi R., S. M. H. Hejazi, M. I. Atri, M. Mirza, Z. Jamzad, T. Safikhan (2012). Karyotype analysis among 10 populations of Thymus eriocalyx (Ronniger) Jalas species in Iran. Annals of Bio. Research., 3 (8): 3916-3925.

[9] Lavania U. C., S. Srivastava (1992). A simple parameter of dispersion index that serves as an adjunct to karyotype asymmetry. J. Bio. Sci., 17(2): 179-182

[10] Levan A., A. Fredga, A. A. Sanderberg (1964). Nomenclature for centromeric position in chromosome. Hereditas, 52: 201-220. 
[11] Paknia R., G. Karimzadeh (2010). Karyotypic study in some Iranian local onion populations. J. of plt. Physio. \& Breeding, 1(1): 49-56.

[12] Peruzzi L., I. J. Leitch, K. F. Caparelli (2009). Chromosome diversity and evolution in Liliaceae. Ann. Bot, 103(3): 459-475.

[13] Srivastava S., H. M. Srivastava (2000). Cytological and karyotypic Studies in four Beta species. J. of Sugar Beet Research, 37(4): 135-142.

[14] Stebbins G. L. (1950). Variation and evolution in plants. Columbia University Press. New York and London. p. 459.

[15] Stebbins G. L. (1971). Chromosomal evolution in higher plants. Edward Arnold Ltd. London. 